\title{
Histological patterns of atherosclerotic plaques in unstable angina patients vary according to clinical presentation
}

\author{
J M Mann, J C Kaski, W I Pereira, S Arie, J A Ramires, F Pileggi
}

\begin{abstract}
Background-Unstable angina is a heterogeneous clinical syndrome. The diverse clinical presentations of unstable angina may reflect different pathogenic mechanisms within the plaque.

Objective-To investigate the cellular constituents of culprit coronary atheromatous plaques in patients with stable angina pectoris and patients with diverse clinical presentations of unstable angina.
\end{abstract}

Methods-48 patients who underwent coronary atherectomy for management of ischaemic heart disease: 23 had stable angina and 25 had unstable angina. Of the latter, 11 patients were classified as Braunwald's IIB and 14 as Braunwald's IIIB unstable angina. The presence of thrombus, cholesterol clefts, and smooth muscle cell proliferation was assessed in atherectomy samples using standard histological techniques. Monoclonal antibodies were used to identify smooth muscle cells and macrophages within atherosclerotic plaque fragments.

Results-Fresh thrombus was more frequently found in patients with Braunwald's IIIB unstable angina (64\%) than in patients with stable angina $(22 \%)$ or IIB unstable angina $(27 \%)(p<0.0006)$. A pattern of smooth muscle cell proliferation ("accelerated progression pattern") was observed which was also associated with coronary thrombus. This pattern was present in $30 \%$ of patients with stable angina, $64 \%$ of patients with IIIB unstable angina, and in all patients $(100 \%)$ with IIB unstable angina. Atherosclerotic plaques with thrombus, cholesterol clefts, and macrophages were more common in patients with unstable angina than in stable angina patients.

Conclusion-The presence of a specific smooth muscle cell proliferation (accelerated progression) pattern in patients with unstable angina, particularly in those with Braunwald's IIB unstable angina, suggests that episodic plaque disruption and subsequent healing may be an important mechanism underlying angina symptoms in these patients.

(Heart 1998;80:19-22)

Keywords: angina pectoris; atherosclerosis; unstable angina; accelerated progression pattern
Unstable angina is a clinically heterogeneous condition in which the severity of the symptoms and the risk of progression to infarction or of sudden death varies widely between reported clinical series. ${ }^{1-4}$ Angiographic studies have identified that in unstable angina a culprit plaque has a characteristic morphology with an irregular eccentric stenosis, often with overhanging edges..$^{5-8}$ In a proportion of cases an intraluminal filling defect indicating a nonocclusive thrombus on the culprit plaque is seen. ${ }^{9-12}$ Pathology studies ${ }^{13}$ showed that these angiographic appearances were caused by plaque disruption in which a mass of thrombus projected into the lumen but antegrade flow was still retained. Projecting thrombi are covered with a layer of activated platelets that embolise as clumps into the intramyocardial vascular bed. ${ }^{14-16}$ These pathological processes have become firmly established as the basis for unstable angina of the crescendo type-that is, at the more severe end of the clinical spectrum. ${ }^{13}{ }^{15-17}$ Studies of necropsy material are innately biased towards the most severe end of any disease spectrum. The introduction of atherectomy allowed plaque material to be obtained from living patients with stable and unstable angina. The general message of such studies $^{18-20}$ was that thrombus occurred more frequently in the material from plaque thought to be responsible for unstable angina than from plaque causing stable angina. Thrombus was, however, neither present in all cases of unstable angina nor absent in all cases of stable angina.

To stratify patients within the wide spectrum of severity of unstable angina, several clinical classifications have been proposed. ${ }^{2}{ }^{21-23}$ Of these, Braunwald's classification ${ }^{23}$ is the most widely used.

The present study examines the relation between atherectomy findings and the different Braunwald groups of unstable angina.

\section{Methods}

PATIENTS

We studied 48 patients ( 41 men and 7 women; mean (SD) age 61 (9) years) with documented coronary artery disease who underwent single vessel directional coronary atherectomy (DCA) at the Institute of Cardiology in Sao Paulo (INCOR), Brazil, and at St George's Hospital, London. At each site, atherectomy was performed by the same experienced operator, and the Simpson Atherocath (Devices for Vascular Intervention, Inc, Redwood City, California, USA) was used in all cases. The specimens retrieved during DCA were fixed in
Accepted for publication 18 February 1998 
Table 1 Clinical and angiographic features in 48 patients who underwent directional coronary atherectomy for treatment of symptomatic ischaemic heart disease

\begin{tabular}{|c|c|c|c|}
\hline & \multirow[b]{2}{*}{$\begin{array}{l}\text { Stable angina } \\
(n=23)\end{array}$} & \multicolumn{2}{|l|}{ Unstable angina } \\
\hline & & $\begin{array}{l}\text { Braunwald IIB } \\
(n=11)\end{array}$ & $\begin{array}{l}\text { Braunwald IIIB } \\
(n=14)\end{array}$ \\
\hline Men & 23 & 10 & 8 \\
\hline Age (years) & $63(9)$ & $57(8)$ & $64(9)$ \\
\hline Hypertension & 6 & 5 & 5 \\
\hline Diabetes mellitus & 2 & 1 & 0 \\
\hline Smoking & 15 & 6 & 6 \\
\hline Family history & 13 & 4 & 7 \\
\hline \multicolumn{4}{|c|}{ Stenosis morphology ${ }^{\star}$} \\
\hline Smooth & 14 & 6 & 5 \\
\hline Complex & 7 & 5 & 6 \\
\hline \multicolumn{4}{|l|}{$\%$ diameter stenosis } \\
\hline At study entry & $64(8) \%$ & $67(12) \%$ & $67.5(8) \%$ \\
\hline Postatherectomy & $25(15) \%$ & $30(11) \%$ & $23(12) \%$ \\
\hline
\end{tabular}

*Angiographic stenosis morphology was assessed in 43 of the 48 patients. Five patients were excluded because of technical difficulties.

$10 \%$ formaldehyde, embedded in paraffin and sent to St George's cardiovascular pathology unit for processing and analysis. In all patients the following clinical variables were assessed: age, sex, and coronary risk factors such as systemic hypertension, diabetes mellitus, cigarette smoking, high plasma cholesterol, and family history of coronary artery disease (table 1 ).

The type of angina pectoris was carefully investigated in each patient using a standardised angina questionnaire. Chronic stable angina (23 patients; group I) was defined as typical exertional angina without change in character, intensity or frequency in the three months before the procedure. Unstable angina was defined as recent onset angina (less than one month), rest angina, and crescendo angina with angina at rest or on minimal exertion. Unstable angina patients $(n=25)$ were divided into two groups according to clinical presentation based on Braunwald's classification. ${ }^{23}$ Group II comprised 11 patients who had episodes of angina at rest in the 30 days preceding angiography but no chest pain at rest in the 48 hours before study entry (Braunwald's IIB). Group III comprised 14 patients who presented with unstable angina and had rest angina in the preceding 48 hours (Braunwald's IIIB).

ANGIOGRAPHIC ANALYSIS

Our technique to analyse coronary artery stenoses has been described in detail elsewhere. ${ }^{24}$ All coronary artery stenoses were selectively assessed by two experienced observers (JCK and WIP). Coronary stenoses were viewed in

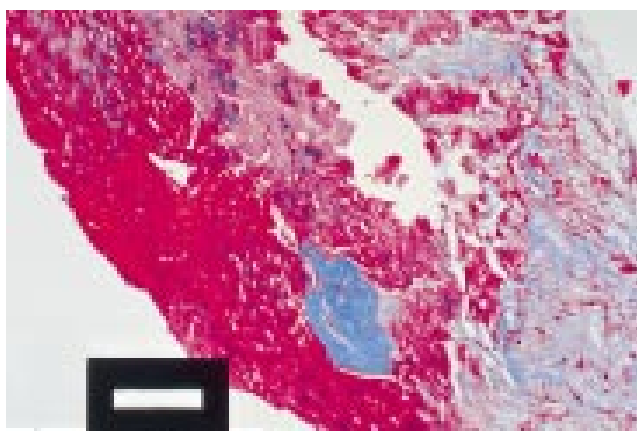

Figure 1 Atherectomy specimen showing thrombus (red) mixed with fragments of connective tissue (blue). (Masson's trichrome stain. Scale $=1500 \mu \mathrm{m}$.)

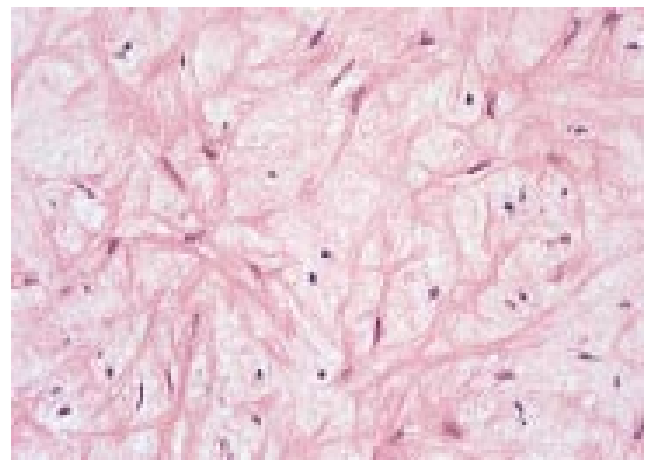

Figure 2 Accelerated progression pattern showing abundant, plump smooth muscle cells in a connective tissue matrix background. (Haematoxylin and eosin stain $\times 40$.)

two orthogonal projections and classified as "complex" or "smooth" using established criteria. ${ }^{52}$ Complex lesions were stenoses with irregular or overhanging edges, or both, showing ulceration or filling defects compatible with the presence of intraluminal thrombus. Smooth lesions had smooth edges, and no complex features.

HISTOLOGICAL ANALYSIS

Histological sections $4 \mu \mathrm{m}$ thick were stained with haematoxylin and eosin, and an elastic stain (elastic van Giesson) to identify the internal elastic lamina and thus gauge the approximate depth of the resection. Other histological variables examined included recent and organising thrombus and cholesterol crystals, both identifiable on the haematoxylin and eosin stained sections. Recent thrombus was defined as the presence of platelets, red blood cells, and fibrin, attached to at least one of the fragments of a specimen (fig 1). The presence of haemosiderin laden macrophages was considered to indicate old haemorrhage. A storiform pattern of smooth muscle cells ${ }^{25}$ in a connective tissue matrix background (fig 2) termed "accelerated progression pattern" was also evaluated on the haematoxylin and eosin stained sections.

Immunocytochemistry was performed on a set of contiguous sections from the same block, using a monoclonal antibody against macrophages (CD 68, Cambridge Biosciences, Cambridge, UK) and another monoclonal antibody against smooth muscle cell actin (SMA, Sigma, Poole, Dorset UK) to identify smooth muscle cells. The avidin biotin complex alkaline phosphatase technique was employed for immunostaining with both antibodies. The presence of either cellular component was evaluated in a semiquantitative manner $(1+$ to $4+)$ by an experienced operator (JM) who was unaware of the clinical state of the patient.

\section{STATISTICAL ANALYSIS}

Differences between samples were assessed with Student's $t$ test, Mann-Whitney test, $\chi^{2}$ test, and Fisher's test as appropriate; $\mathrm{p}<0.05$ was considered significant.

\section{Results}

CLINICAL PRESENTATION AND ANGIOGRAPHIC FINDINGS

Table 1 summarises the clinical features in the 48 patients included in the study. Coronary 
Table 2 Histological features of coronary atherosclerotic plaques in 48 patients undergoing directional coronary atherectomy for treatment of symptomatic ischaemic heart disease

\begin{tabular}{llll}
\hline & & \multicolumn{2}{c}{ Unstable angina } \\
\cline { 3 - 4 } & $\begin{array}{l}\text { Stable angina } \\
(n=23)\end{array}$ & $\begin{array}{l}\text { Braunwald IIB } \\
(n=11)\end{array}$ & $\begin{array}{l}\text { Braunwald IIIB } \\
(n=14)\end{array}$ \\
\hline Thrombus & $5(22 \%)$ & $3(27 \%)$ & $9(64 \%)$ \\
Cholesterol & $4(17 \%)$ & $3(27 \%)$ & $6(43 \%)$ \\
AP pattern & $7(30 \%)$ & $11(100 \%)$ & $9(64 \%)$ \\
\hline AP, accelerated progression. & &
\end{tabular}

artery disease risk factors were not significantly different when the three patient groups were compared. All patients were receiving aspirin at the time of atherectomy, but none of them was receiving oral anticoagulation. The time interval between diagnostic coronary angiography and atherectomy ranged from 1 to 10 days in the three patient groups.

Detailed angiographic assessment of the target coronary artery lesions before DCA was carried out in 43 of the 48 patients. In the remaining five patients, technical problems precluded adequate angiographic analysis. Of the 43 target coronary artery stenoses analysed $18(42 \%)$ were complex with ragged irregular edges, and 25 (58\%) were smooth. Thrombus was angiographically diagnosed in three unstable angina patients (14\%). Target stenoses were complex in seven of 21 patients $(33 \%)$ with stable angina pectoris and in 11 of 22 $(50 \%)$ unstable angina patients $(\mathrm{p}<0.05)$.

HISTOLOGICAL FINDINGS

An average of five fragments of tissue from each patient per atherectomy specimen (range 1-10) was obtained. Table 2 summarises the main histological findings in the 48 patients studied. Thrombus was significantly $(\mathrm{p}<0.015)$ more common in patients with Braunwald IIIB unstable angina (64\%), compared to patients with stable angina $(22 \%)$ and IIB unstable angina $(27 \%)$.

Cholesterol crystals were present in 13 of the 48 specimens (27\%). Only four of the 23 patients with stable angina had cholesterol crystals $(17 \%)$ compared with six of the 14 patients $(43 \%)$ with Braunwald IIIB unstable angina. Cholesterol crystals in the atherectomy specimen were significantly associated with the presence of thrombus; of the 17 patients with thrombus, 10 had cholesterol crystals (59\%), whereas only three of the 31 patients without thrombus had cholesterol crystals $(19 \%$; $p=0.0006)$. No significant differences were found among the three groups in the number of macrophages or smooth muscle cells. There was no significant association between a high number of monocytes in the atherectomy specimen and the presence of cholesterol crystals.

The accelerated progression pattern of smooth muscle proliferation was found in 27 of the 48 patients $(56 \%)$. This histological pattern was observed in seven of 23 patients with stable angina (30\%), nine of 14 patients with Braunwald IIIB unstable angina (64\%), and in all 11 patients with Braunwald IIB unstable angina $(100 \%)(p=0.0002)$.

\section{Discussion}

Progression of coronary artery disease is neither linear nor predictable. ${ }^{27}$ Studies have shown that patients with unstable angina have an angiographic progression rate of $44 \%$ at 13 months. $^{28}$ Recently, Chen and colleagues ${ }^{29}$ showed that, even in patients with unstable angina who stabilise rapidly on medical treatment, progression of coronary artery disease is a common phenomenon. Rapid coronary stenosis progression has also been observed in patients with chronic stable angina pectoris awaiting coronary angioplasty. ${ }^{30}$

Pathology studies of postmortem material show a close relation between intracoronary thrombosis and acute ischaemic events such as myocardial infarction and unstable angina. ${ }^{15-17}$ The findings of our atherectomy study agree with those of others, ${ }^{9-12}$ showing that patients with unstable angina have a significantly higher incidence of coronary thrombosis compared with patients who have stable chronic angina. Our study, in common with others, also shows that a sizeable proportion of samples taken from the culprit lesions regarded as responsible for unstable angina do not contain thrombus. In one study, for example, thrombus was found in only $22 \%$ of samples. ${ }^{18}$

There are a number of possible explanations for the absence of thrombus in atherectomy samples taken from unstable angina patients. One explanation is that pure coronary spasm may have been responsible for the angina. ${ }^{31}$ Another is that specimens of plaque obtained by atherectomy may miss the thrombus. This view is supported by the higher frequency of thrombus reported in angioscopic studies of unstable angina. ${ }^{32} \mathrm{~A}$ final more plausible explanation lies in the time between the onset of symptoms and when the atherectomy sample is taken. This interval varies considerably in all the series reported to date. ${ }^{9-12}$ Thrombus within or on the surface of a plaque is rapidly lysed or initiates proliferation of smooth muscle cells, which will replace the thrombus with connective tissue. Flugelman et al found thrombus to be present in only $34 \%$ of patients with unstable angina but emphasised that accelerated smooth muscle proliferation was found in the remaining cases. ${ }^{26}$

The relation between thrombus formation and the induction of smooth muscle proliferation after angioplasty is well recognised. ${ }^{33}$ Smooth muscle cells obtained at atherectomy proliferate more rapidly if the sample also contained thrombus. ${ }^{34}$ Flugelman et al postulated that one credible explanation for their findings was that the atherectomy samples had been taken at a stage when thrombus had vanished but active smooth muscle cell proliferation was still continuing. ${ }^{26}$ The results of our study are entirely consistent with this view. All of the samples taken from patients with Braunwald IIB unstable angina, where the symptoms had occurred days or weeks before intervention, had accelerated smooth muscle proliferation. In the samples from the Braunwald IIIB unstable angina patients, thrombus was more common and smooth muscle proliferation less 
frequent, findings consistent with the short interval between symptoms and atherectomy.

Previous atherectomy studies have found that a small proportion of plaques responsible for chronic stable angina also have thrombus. $^{9-12}$ Our study extends this work by showing that accelerated smooth muscle proliferation is also found in apparently stable plaques. These facts endorse the view that silent plaque progression can be caused by occult thrombosis and are consistent with recent findings ${ }^{30}$ showing that in stable angina angiographically complex coronary stenoses may progress rapidly.

1 Braunwald E, Jones RH, Mark DB, et al. Diagnosing and managing unstable angina. Circulation 1994;90:613-22.

2 managing unstable angina. Circulation 1994;90:613-22. history of unstable angina with medical or surgical therapy. history of unstable angin

3 White LD, Lee TH, Cook EF, et al. Comparison of the natural history of new onset and exacerbated chronic ischemic heart disease. F Am Coll Cardiol 1990;16:304-10.

4 Farhi J-I, Cohen M, Fuster V. The broad spectrum of unstable angina pectoris and its implications for future controlled trials. Am F Cardiol 1986;58:547-50

5 Ambrose JA, Winters SL, Stern A, et al. Angiographic morphology and pathogenesis of unstable angina pectoris. Am f Coll Cardiol 1985;5:609-16.

6 Haft JI, Goldstein JE, Niemiera ML. Coronary arteriographic lesion of unstable angina. Chest 1987;92:609-12.

7 Cowley MJ, DiSciascio G, Rehr RB, et al. Angiographic observations and clinical relevance of coronary thrombus $13 \mathrm{E}$.

8 Bugiardini R, Pozzati A, Borghi A, et al. Angiographic morphology in unstable angina and its relation to transient myocardial ischemia and hospital outcome. Am 7 Cardiol 1991;67:460-4.

9 Bresnaham DR, Davies JL, Holmes DR, et al. Angiographic occurrence and clinical correlates of intraluminal coronary artery thrombus. Role of unstable angina. $7 \mathrm{Am}$ Coll Cardio 1985;6:285-9.

10 Gotoh K, Minamino T, Katoh O, et al. The role of intracoronary thrombus in unstable angina: angiographic assessment and thrombolytic therapy during ongoing anginal attacks. Circulation 1988;77:526-34.

11 Sherman CT, Litvack F, Grundfest W, et al. Coronary angioscopy in patients with unstable angina pectoris. $N$ Engl $\mathcal{F}$ Med 1986;315:913-9.

12 Mizuno K, Satomura K, Miyamoto A, et al. Angioscopic evaluation of coronary-artery thrombi in acute coronary syndromes. N Engl f Med 1992;326:287-91.

13 Davies MJ. Stability and instability. Two faces of coronary

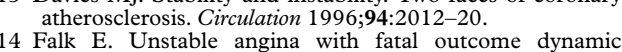
coronary thrombosis leading to infarction and/or sudden death: autopsy evidence of recurrent mural thrombosis with peripheral embolization culminating in total vascular occlusion. Circulation 1985;71:699-708.
15 Davies MJ, Thomas AC. Plaque fissuring - the cause of acute myocardial infarction, sudden ischaemic death and acute myocardial infarction, sudden ischaemic
crescendo angina. Br Heart $\mathcal{f}$ 1985;53:363-73.

16 Davies MJ, Richardson PD, Woolf N, et al. Risk of thrombosis in human atherosclerotic plaques: role of extracellular ipid, macrophage, and smooth muscle cell content. $\mathrm{Br}$ Heart $f$ 1993;69:377-81.

17 Falk E. Plaque rupture with severe pre-existing stenosis precipitating coronary thrombosis. Br Heart f 1983;50:12734.

18 Escaned J, van Suylen RJ, MacLeod DC, et al. Histologic characteristics of tissue excised during coronary atherectomy in stable and unstable angina pectoris. Am f Cardiol 1993;71:1442-7.

19 Escaned J, deJong M, Eng B, et al. Clinical and histological determinants of smooth muscle cell outgrowth in cultured atherectomy specimens: importance of thrombus organisation. Coron Artery Dis 1993;4:883-90.

20 Annex BH, Denning SM, Channon K, et al. Differential expression of tissue factor protein in directional atherectomy specimens from patients with stable and unstable coronary syndromes. Circulation 1995;91:619-22.

21 Chahine RA. Unstable angina: the problem of definition. $\mathrm{Br}$ Heart $\mathcal{F}$ 1975;37:1246-7.

22 Maseri A. Pathogenetic classifications of unstable angina as a guideline to individual patient management and prognosis. Am F Med 1986;80:48-55.

23 Braunwald E. Unstable angina: a classification. Circulation 1989;80:410-14.

24 Kaski JC, Tousoulis D, Haider AW, et al. Reactivity of eccentric and concentric coronary stenoses in patients with chronic stable angina. $7 \mathrm{Am}$ Coll Cardiol 1991;17:627-33.

25 Levin D, Gardiner G. Complex and simple coronary artery stenosis: a new way to interpret coronary angiograms based on morphologic features of lesions. Radiology 1987;164: 675-80.

26 Flugelman MY, Virmani R, Correa R, et al. Smooth muscle abundance and fibroblast growth factors in coronary esions of patients with nonfatal unstable angina. Circulation 1993;88:2493-500.

27 Bruschke AVG, Kramer JR, Bal ET, et al. The dynamics of progression of coronary atherosclerosis studied in 168 medically treated patients who underwent coronary arteriography three times. Am Heart f 1989;117:290-305.

28 Rafflenbeul W, Smith L, Rogers W, et al. Quantitative coronary arteriography: coronary anatomy of patients with unstable angina pectoris reexamined 1 year after optional medical therapy. Am f Cardiol 1979;43:699-707.

29 Chen L, Chester MR, Redwood S, et al. Angiographic tenosis progression and coronary events in patients with "stabilized" unstable angina. Circulation 1995;91:2319-24. progression of coronary artery disease in patients with ngina pectoris. The role of complex stenosis morphology. Circulation 1995;92:2058-65.

31 Bogaty P, Hackett D, Davies G, et al. Vasoreactivity of the culprit lesion in unstable angina. Circulation 1994;90:5-11.

32 White C, Ramee S, Collins T, et al. Coronary thrombi increase PTCA risk. Angioscopy as a clinical tool. Circulation 1996;93:253-8.

33 Schwartz RS, Holmes DR, Topol EJ. The restenosis paradigm revisited: an alternative proposal for cellular paradigm revisited: an alternative proposal for

34 MacLeod DC, Strauss BH, deJong M, et al. Proliferation and extracellular matrix synthesis of smooth muscle cells cultured from human coronary atherosclerotic and restenotic lesions. $\mathcal{F}$ Am Coll Cardiol 1994;23:59-65 